\title{
An Observation of the Mast Cell, especially the Dendrite-Type Tissue Mast Cell in Triturus pyrrhogaster (Boie)
}

\author{
By \\ Takao Setoguti and Yutaka Yonemoto \\ First Department of Anatomy, Gifu University Medical School \\ Gifu, Japan
}

There have been many morphological studies on mast cells in various animals, and also in Japanese newt, Triturus pyrrhogaster (Boie), M i u ra (1932), O h u ye (1952), and $\mathrm{H}$ a t a i et al. (1958) have already reported on these. However, they have not observed tissue mast cells having long processes which seem to be characteristic to this species.

Using spread-preparations of peritoneum and mesentery, we observed dendrite-type specific tissue mast cells except ordinary ones. The result obtained will be reported as follows.

\section{Material and Method}

The experimental material consisted of adult Triturus pyrrhogaster (Boie) captured in the suburbs of Gifu city and kept in a tank containing tap water for at least half a year.

In these animals, a longitudinal incision was made on the skin of the abdomen, and the skin being opened, the peritoneum was exposed and cut off as wide as posible. In some of the newts also their mesenteries were taken.

The tissues were spread on the slide glass, and these tissue spreads of peritoneum and mesentery were immediately fixed in a C a r noy's solution, absolute ethanol, 4\% lead acetate solution, or $\mathrm{H}$ e $1 \mathrm{l}$ y's fluid and stained with 0.1 to $0.5 \%$ toluidine blue solution buffered at $\mathrm{pH} 3.2$ with $1 / 10 \mathrm{M}$ veronal acetate for 5 to 15 minutes. Some of the tissue spreads fixed in C a r n o y's solution were stained by M c Man us method of PAS-reaction. These preparations were dehydrated in graded ethanols and mounted in Canada balsam.

As a control, the abdominal skin with peritoneum embedded in paraffin and cut longitudinally to make serial sections was stained 
with the same method as mentioned above.

\section{Observations}

In the spread preparations, the nuclei of peritoneal epithelium are diffusely scattered, oval or round in shape and flattened, being filled with orthochromatically weakly stained chromatin networks. Among these nuclei there are small, strongly orthochromatic, elliptic nuclei often in groups and small numbers of dark orthochromatic, segmentary nuclei.

The former are the nuclei of erythrocytes and may be readily distinguished by preparations fixed in $\mathrm{H}$ ell y's fluid. The latter are the nuclei of polymorphonuclear leucocytes.

In some fields, we can find the long spindle shaped nuclei arranged in a double or triple line run and these are the nuclei of endothelial cells of a capillary.

Besides these many orthochromatically stained nuclei, there are a few cells filled with metachromatically stained, reddish purpule or bluish purple granules. These are mast cells.

Within the capillaries, the mast cells can be classified into two types; i. e. the round or elliptic, mulberry-form cells whose nuclei are densely covered with bluish purple granules and can hardly be identified, and the round or elliptic ones in which nuclei are less densely covered with bluish purple, smaller granules and can be seen round or elliptic. The latter occasionally contain also few orthochromatic granules. (Fig. 1).

Outside the capillaries, except the same sorts of mast cells as mentioned above-some of them may come from capillaries during preparation-there are other fairly large mast cells containing reddish purple, less dense granules and a round or elliptic nucleus.

Among these cells there are ones in which granules are swollen and their stainability becomes lower and granules occasionally are fused together. (Fig. 2).

Sometimes, we can see the granules of various size dispersed out of the cell bodies. This phenomenon seldom can be seen also in the mast cells within the capillaries.

In addition, there occasionally are the cells which have dark nuclei seeming to be pyknotic and smaller granules that are more loosely distributed and sometimes thought to be disappeared.

The size of the ordinary mast cells is usually 15 to $20 \mu$ in long diameter and 6 to $10 \mu$ in short diameter, and sometimes, they have 
tail-like processes filled with granules.

The nucleus is located centrally or eccentrically, and the length varied from about 10 to $16 \mu$ and the width from 6 to $10 \mu$.

However, besides these ordinary cells, we can sie the specific cells from which the long dendrite-like, snaked processes filled with metachromatic reddish purple granules strech in all directions (Fig. 5). In general, the processes tend to lie in fragments, but we have also observed the almost perfect ones. They are disposed in a even plane and appear from two opposite polar prolongations (Fig. 4) to five polar ones (Fig. 3). Furthermore, they are characterized by the presence of many branches-we can see secondary to fourth branch -and knot-like swellings (Fig. 5). But, occasionary, we can also see the processes having the same thickness to distal end.

In general, the cell body is identified by its single, frequently, palely stained, large nucleus and surrounding metachromatic granules.

The nucleus is flattened and oval or round, occasionally kidneyshaped, and its flat surface is only partially covered with granules. The size of the nucleus is 10 to $30 \mu$ in long diameter and 6 to $15 \mu$ in short diameter.

The granules of this cell are thought to be stained more reddish than those of the ordinary cell.

The distance between the nucleus and the distal end of the process is about $3 \mathrm{~mm}$ in the longest.

We can see that processes of one cell ran across those of another or their distal ends contact with those of other cells to form an extensive network. In other cases, the processes accompany or traverse, and occasionally surrouuded the capillaries. The granules within the cell body and process show PAS-negative reactions.

Besides these cells, there are a few cells thought to be degenerating; their nuclei are smaller and spindle in shape and are stained darkly, and their processes thinner and shorter.

Findings mentioned above are observed in both peritoneal and mesenterial connective tissues.

On the ordinary paraffin sections used as a control, the process filled with metachromatic granules is only seen as fragments.

\section{Discussion}

There have been few morphological studies on the mast cell in Japanese newts.

M i u r a (1932) has systematically researched using various organs 
and reported that the mast cells are long elongated in form; the large ones are 6.3 to $12.5 \mu$, and the long ones are constricted in several portions and have a beaded appearance and have a tendenc to extend processes. However, using paraffin sections, he could not observe the long dendrite-like processes.

Then, O h u y e (1952) has observed blood mast cells and described that the shape of basophils are round, spindle or occasionally stellata. But on his figures, their processes are only the same length of the cell body at the longest. It agrees to our observations that according to his findings the granules show a good deal of variation in size (about 0.2 to $2 \mu$ in diameter), but we have never seen such a granular formation from the nuclei as he observed.

$\mathrm{H}$ a t a i et al. (1958) has studied on the blood mast cells and the tissue mast cells of the mesentery, and he reported that most of the mast cells located in the walls of blood vessels spread their granules out of the cell body, and occassionally they have the long processes containing granules to distal end.

However, on their microscopic photographs, the processes are only tail-like in shape and far shorter than those of our dendritetype mast cells.

Further, they have mentioned that the mast cells with dispersion of granules occur inside the blood vessels, and never outside the latter; but we could see those outside, rather than inside.

On the stainability of granules, we observed a reddish tint to be stronger outside the blood vessels than inside them, in opposition to their findings.

$\mathrm{R}$ ile y (1953) studied on the mast cells in the subcutaneous tissues, mesentery, and greater omentum of a rat. He stained with toluidine blue and classified them into two types: the type-1 mast cells having also orthochromatic granules exist in the adventitia of the blood vessels with muscle coat, and the type-2 mast cells containing only metachromatic granules lie around the capillaries and the tissue isolated. He have suggested that the former are younger and the more immature type of the latter. However, the blood vessels we have observed are almost the capillaries.

We could observe the mast cells containing both orthochromatic and metachromatic smaller granules outside the capillaries, or rather more frequently inside them: we could never find orthochromatic granules in the dendrite-type mast cells. The latter are thought to be the highest-differentiated and mature cells.

Outside the capillaries, there occasionally are the ordinary type 
mast cells in which the metachromatic granules are swollen and their stainabilities are lower. These are thought to be the same cells as the degenerate cells which $\mathrm{Riley}$ had demonstrated and may coinside with the light cell type mast cell having been electronmicroscopically observed by Seto $\mathrm{g} \mathrm{u}$ t and $\mathrm{Nak}$ a m u ra (1963).

Except the ordinary type mast cells mentioned above, we could also observe the dendrite-type specific tissue mast cells having metachromatic, more smaller granules.

On such a type of mast cells, $R$ a $n$ vie $r$ as long ago as 1890 described that in the peritoneum of Triton cristatus, Salamandra maculosa, and etc. he observed "de cellules fusiformes ou arboisées" which was $1 . \mathrm{mm}$ in length and had fine granules and processes with swellings and the latter could be constricted, and he called them "clasmatocytes"-cells which cast off fragments of protoplasm.

His findings have well coinsided with our observations. $\mathrm{He}$ mentioned that this cell could not anastomose each other to form a network, but we occasionally could see an extensive network made of their processes. Occassionally, we have observed the processes having the same thickness to distal end. Judging from this fact, the knotlike swellings and constrictions may be the artifacts which occured during preparation of the tissues.

S c h a e r and Eder (1962) have studied, staining with toluidine blue solution of different $\mathrm{pH}$, on the mast cells of rats from early embryonal stage till the 20th day after birth. According to them, in the early mast cells, neutral mucopolysaccharides appear first and then are gradually transformed into acid mucopolysaccharides containing $\mathrm{SO}_{3} \mathrm{H}$-groups.

Using the toluidine blue solution buffered at $\mathrm{pH} 3.2$, also our metachromatically stained granules are confined to acid mucopolysaccharides containing $\mathrm{SO}_{3} \mathrm{H}$-groups, so that orthochromatic granules are thought to be more immature ones. In the connective tissues of the peritoneum and mesentery, there exist only a few immature mast cells in which both metachromatic and orthochromatic granules are mixed.

From this fact and Ohuye's findings of blood mast cells, it is felt that the mast cells in the peritoneum and mesentery may be generated in other regions and transported by the capillaries to stay there.

With regard to the genesis of mast cells in various animals, there are different theories; the fibroblast theory, the endothelium cell theory, the leucocyte theory, and etc. 
However, on the mast cells within the peritoneum and mesentery in newts, we can not but agree to $\mathrm{M}$ a ximow's following wards: In lower vertebrates the connective tissue mast cells are intimate related to the basophilic blood leucocytes and may originate from them through direct transformation after emigration out of the blood vessels.

Nevertheless, the dendrite-type mast cells are distinguished from the ordinary type mast cells not only in their form but also in the size and stainability of nuclei and the size of granules. Therefore we need further studies to explain the questions whether these both cell types have a common genesis or not.

\section{Summary}

Using spread-preparations stained with toluidine blue buffered at $\mathrm{pH} 3.2$, the mast cells in the peritoneum and mesentery of adult Triturus pyrrhogaster (Boie) were observed.

1. Inside the capillaries, there are mainly the mulbeery-form mast cells filled densly with bluish purple granules, and the occasional immature mast cells in which both metachromatic and orthochromatic smaller granules are loosly mixed.

2. Outside the capillaries, there exist, besides the same sort of mast cells as seen inside the capillaries, other large mast cells in which granules are bigger and reddish purple and occasionally some of them are dispersed out of the cell bodies, and few remarkable dendrite-type specific mast cells.

3. The latter extend the long dendrite-like, snaked processes filled with smaller, metachromatic granules in all directions, and tend to anastomose each other to form an extensive network. And they are distinguished from the ordinary type mast cells not only in their shape but also in the size and stainability of the nuclei and the size of the granules.

4. The mast cells seem to be the ones which emigrated from other regions by the capillaries and were full growth there.

\section{Literature cited}

1) Hata i, T., Hashimoto, T., Nag a o, T. and Sakagawa, K. 1958: Studies on mast cells. I. Observation by methyl green-pyronin or methyl green-toluidine blue method. J. med. Soc. Toho Univ., 5, 95-98. (Jap.).

2) Maximow, A. 1924: Relation of blood cells to connective tissues and endothelium. Physiol. Rev., 4, 533-563. 
3) M i u r a, N. 1932: Histological comparative studies on tissue mast cells in various animals. J. Tohoku Igaku Z., 14, 1-64. (Jap.).

4) Ohuye, T. 1952: Supplementary observations of the basophilic granulocyte of the newt, Triturus pyrrhogaster, with special reference to those of some invertebrates. Memoris of the Ehime University, Sect. 2, 1, 193-199.

5) Ranvier, M.L. 1890: Des clasmatocytes. Comt. Rend. Acad. Sci. (Paris), 110, 165-169.

6) Riley, J.F. 1953: The relationship of the tissue mast cells to the blood vessels in the rat. J. Path. Bact., 65, 461-469.

7) Schauer, A. und Eder, M. 1952: Die Entwicklung von Mucopolysacchariden und Bildung histochemisch nachweisbarer Enzyme während der Mastzellreifung. Virch. Arch. Path. Anat., 335, 72-83.

8) Setoguti, T. and $\mathrm{Nakamura}, \mathrm{H}$. 1963: The fine structure of tissue mast cells in Triturus pyrrhogaster (Boie). Arch. Hist. Jap., 23, 311-335.

\section{Explanation of Plates}

Fig. 1. Ordinary type mast cell in a capillary of the peritoneum of a newt. Three mulberry-form cells whose nuclei are completely covered with metachromatic granules $(M)$ and one cell in which both metachromatic and orthochromatic smaller granules are $\operatorname{mixed}(\mathrm{m})$ are observed among dark nuclei of erythrocytes. Magnification $800 x$.

Fig. 2. A degenerated ordinary type tissue mast cell in which metachromatic granules are swollen and their stainability becomes lower(M). In the bottom of the figure is seen a blood capillary containing several erythrocytes. Magnification. $800 \times$.

Fig. 3. A dendrite-type specific tissue mast cell in the peritoneum of a newt. A large nucleus $(\mathrm{N})$ and surrounding cell body stretching five long processes filled with small granules are seen. A cleft of the cell body is thought to be a artifact. e, nucleus of erythrocyte. p, nucleus of peritoneal epithelium. Magnification $800 \times$.

Fig. 4. A dendrite-type specific tissue mast cell, bipolar type one, whose process traverses a blood capillary which runs longitudinally in the center of the figure. M, cell body of the dendrite-type cell. Magnification $600 \times$.

Fig. 5. Dendrite-type specific tissue mast cells in the peritoneum of a newt. Note long dendrite-like, snaked processes streching in all directions and their occasional anastomosis with each other. Arrow, cell body of the dendrite-type cell. Magnification $160 \times$. 
Plate I
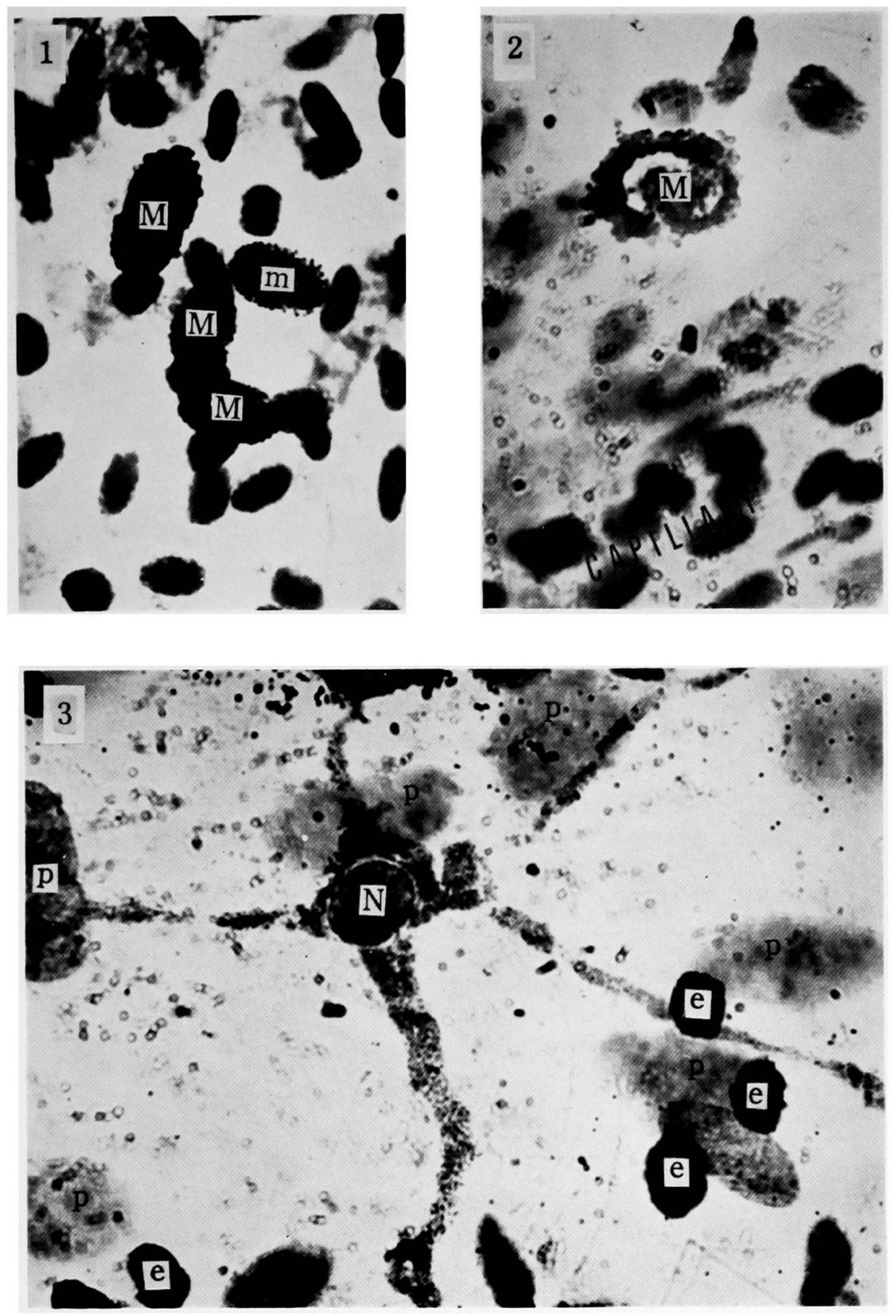

T. Setoguti and Y. Yonemoto 
Plate II
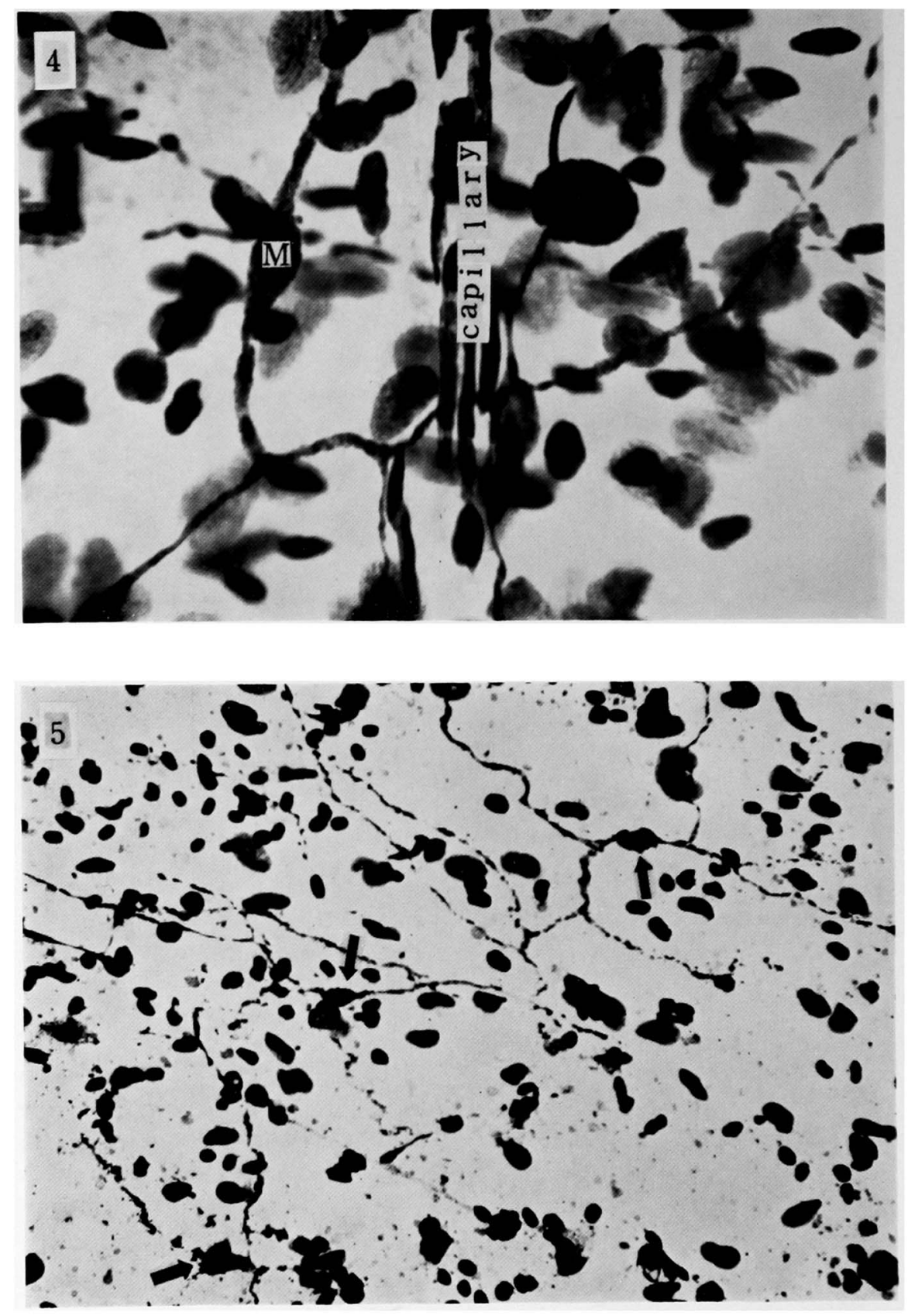

T. Setoguti and Y. Yonemoto 